Marquette University

e-Publications@Marquette

College of Nursing Faculty Research and

Publications

Nursing, College of

$1-1-2017$

Effectiveness of a Natural Family Planning Service Program

Richard Fehring

Marquette University, richard.fehring@marquette.edu

Mary Schneider

Marquette University, mary.schneider@marquette.edu

Accepted version. MCN: American Journal of Maternal Child Nursing, Vol. 42. No. 1 (January/ February 2017): 43-49. DOI. (C) 2017 Wolters Kluwer Health, Inc. Used with permission. 


\title{
Effectiveness of a Natural Family Planning Service Program
}

\author{
Richard J. Fehring \\ College of Nursing, Institute for Natural Family Planning, \\ Marquette University, \\ Milwaukee, WI \\ Mary Schneider \\ College of Nursing, Institute for Natural Family Planning, \\ Marquette University, \\ Milwaukee, WI
}

\begin{abstract}
Purpose: The aims of this study were to determine and compare extended use-effectiveness of an online nurse-managed fertility education service program among women (and subgroups of women) seeking to avoid pregnancy.

Study Design and Methods: This was a 24-month prospective study of a university-based online Web site with 663 nonbreastfeeding women using an online charting system to avoid pregnancy. Participants tracked their fertility online with either cervical mucus monitoring, electronic hormonal fertility monitoring, or both fertility indicators. Unintended pregnancies were validated by professional nurses.
\end{abstract}


NOT THE PUBLISHED VERSION; this is the author's final, peer-reviewed manuscript. The published version may be accessed by following the link in the citation at the bottom of the page.

Results: Participants had a mean age of 30.4 years $(S D=6.3$ ) and mean 1.7 children $(S D=2.0)$. Among the 663 nonbreastfeeding participants there were 2 unintended pregnancies per 100 at 24 cycles of correct use and 15 pregnancies at 24 cycles of typical use. However, the 212 women using the electronic fertility monitor had a typical use unintended pregnancy rate of 6 at 24 cycles of use in comparison with the 118 women using cervical mucus monitoring that had a typical use pregnancy rate of 19 at 24 cycles and with the 333 women using both fertility indicators that had a pregnancy rate of 18 at 24 cycles of use.

Clinical Implications: Use of the fertility monitor to estimate fertility among nonbreastfeeding women provides the most secure method of avoiding pregnancy.

Key words: Contraception; Family planning; Fertility; Hormone fertility monitor; Natural family planning

In 1998, an Institute for Natural Family Planning was established at Marquette University College of Nursing to provide professional education, research, and service in natural family planning (NFP). In 1999, a new method of NFP (called the Marquette Model or MM) was developed and launched that entailed use of an algorithm, integration of electronic hormonal fertility monitoring, and traditional natural markers of fertility. In 2007, the first prospective efficacy study of MM was published (Fehring, Schneider, Raviele, \& Barron), followed by a retrospective effectiveness study (Fehring, Schneider, \& Barron, 2008). A comparison effectiveness study between MM and an older cervical mucus method found the newer system of NFP more effective in helping women avoid pregnancy (Fehring, Schneider, Barron, \& Raviele, 2009).

In 2008, a web program to teach couples the MM of NFP and to provide online consultation was launched to offer ease of access for couples across the United States. This site (http://nfp.marquette.edu) includes information on NFP, user forums, a menstrual cycle charting system, protocols for special reproductive circumstances (e.g., monitoring fertility during the postpartum breastfeeding transition), and online support from nurses and physicians. The online MM system now has over 10,000 women/couples who have registered. Until May of 2015, these services were provided free, even though they required 30 minutes to 3 hours per day of professional consultation.

In 2011, a pilot study on the effectiveness of the Web site system in helping women avoid pregnancy was published (Fehring, Schneider, \& Raviele, 2011). Two years later a randomized

MCN: American Journal of Maternal Child Nursing, Vol 42, No. 1 (January/February 2017): pg. 43-49. DOI. This article is (C) Wolters Kluwer Health, Inc. and permission has been granted for this version to appear in e-Publications@Marquette. Wolters Kluwer Health, Inc. does not grant permission for this article to be further copied/distributed or hosted elsewhere without the express permission from Wolters Kluwer Health, Inc. 
comparison study, with a sister research Web site, that compared use of an electric hormonal fertility monitor with monitoring cervical mucus changes as indicators for the fertile phase was conducted and showed use of the fertility monitor was more effective than use of cervical mucus monitoring in avoiding unintended pregnancy (Fehring, Schneider, Raviele, Rodriguez, \& Pruszynski, 2013). A study to determine the influence of motivation on the MM effectiveness demonstrated that motivation was a big factor in NFP effectiveness (Fehring, Schneider, Barron, \& Pruszynski, 2013), and a study to compare length of required abstinence between use of the electronic fertility monitor and cervical mucus monitoring indicated use of the fertility monitor required significantly less abstinence than cervical mucus monitoring (Fehring \& Schneider, 2014).

The NFP Web site system facilitated studies to determine effectiveness of special protocols for postpartum women (Bouchard, Fehring, \& Schneider, 2013), effectiveness to avoid pregnancy among women transitioning through perimenopause (Fehring \& Mu, 2014), and effects of focused intercourse during the estimated fertile window with couples wishing to achieve pregnancy (Mu \& Fehring, 2014). The Web site enabled provision of women's health beyond family planning in that the nurses managing the Web site and user forum answered many related health questions (e.g., assessing and managing polycystic ovarian syndrome and unusual uterine bleeding) with (as of February 2016) over 20,000 posts. These studies demonstrated the online NFP Web site was a system of providing women's healthcare and use of the menstrual cycle as a vital sign.

Efficacy and effectiveness studies of the MM system of NFP for avoiding pregnancy are based on use of NFP through 12 months or 12 to 13 menstrual cycles of use. However, Trussell (2011) has pointed out that effectiveness of methods of family planning and in particular those that require behaviors for effectiveness will have increasing unintended pregnancy rates over time. There have been few studies of extended use-effectiveness with NFP methods. Researchers at the Georgetown University Institute for Reproductive Health found that extended use of the Standard Days Method continued to be effective 2 to 3 years after initiation to avoid pregnancy (Sinai, Lundgren, \& Gribble, 2012). The aims of this study were to determine and compare extended use-effectiveness (i.e., at 12 and 24 menstrual 
NOT THE PUBLISHED VERSION; this is the author's final, peer-reviewed manuscript. The published version may be accessed by following the link in the citation at the bottom of the page.

cycles of use) of the MM online system of NFP among women (and subgroups of women) seeking to avoid pregnancy.

\section{Methods}

Sample

All participants were obtained from April of 2008 through April of 2015 by one announcement of the new Marquette University NFP Web site in an online discussion forum for NFP healthcare professionals. Availability of the Web site then spread through online "snow-ball" means, that is, from one participant to another or by other participants posting the availability of the Web site in blogs or other Web sites, and a user-initiated social network. Eligibility was that the female participant wished to use the site to avoid pregnancy and had at least one menstrual cycle of charting. At registration into the Web site, participants were asked to sign (i.e., click on a "yes" response) an online consent form that requested they use the site and charting system and provide feedback to the developers. Participants were not able to use the Web site charting system or forums until consent was given. There were 1,530 participants who met inclusion criteria. The 663 participants who were using the site to avoid pregnancy were not breastfeeding, and 18 years or older are the focus of this report. The ongoing evaluation study of the MM online NFP system has received continued evaluation and approval from the Marquette University Office of Research Compliance.

\section{Online NFP Web Site}

The Marquette University College of Nursing NFP Web site (http://nfp.marquette.edu) has free information on fertility health, short instructional videos, downloadable menstrual cycle charts, access to protocols for special circumstances (e.g., using NFP while breastfeeding), instructions on how to observe and chart natural indicators of fertility, and instructions for achieving and avoiding pregnancy. A unique aspect of the information section of the Web site is a one-page simple Quick Start Instructions that can be read in 5 minutes and allows users to begin charting and using the NFP method almost immediately. Women who register on the site have access to discussion forums and consultation from nurse NFP teachers, an obstetrician gynecologist with expertise in the use of NFP, and a bioethicist. The online charting system also notifies the user of 
possible health problems, including unusual bleeding, infertility, pregnancy, and cycle dynamics that are out of the norm.

Nurses that manage the online program visit the site daily to answer questions in the online forums, to provide one-on-one private consultation with participants, and to monitor the site for inappropriate posts. The forum and private message questions are answered within 24 hours of being published. Nurses notify the physician consultant or bioethicist when questions are directed toward their expertise. The nurses periodically update the Web site with research on fertility, suggestions on how to manage women's health problems like polycystic ovarian disease, and how to optimize fertility.

The online charting system has designated sections for recording results of either an electronic hormonal fertility monitor or self-observed cervical-vaginal mucus (as estimates of the fertile phase of the menstrual cycle) and provides spaces for recording the results as $L=$ low, $H=$ high, or $P=$ peak fertility (Figure 1 ). The charting system provides a pop-up window for users that illustrates the three fertility levels provided by the fertility monitor or cervicalvaginal mucus observations. The charting system also has a place to record menses on a scale of $1-3$ with $1=$ light, $2=$ moderate, and 3 = heavy menstrual flow and a row for recording acts of intercourse ("I"). The chart has room for recording intention of use (achieve or avoid pregnancy) for each cycle. The system automatically indicates (in light blue) the fertile phase (based on a built in fertility algorithm) as the user charts. There is no guessing whether the day is fertile or not.

Participants can use the charting system and the MM of NFP with either the fertility monitor or cervical mucus monitoring or both indicators. The online system automatically calculates the estimated fertile window based on the algorithm that indicates the beginning of the fertile phase for the first six cycles to be day 6 , then after six cycles, the earliest Peak minus 6 days. The end of the fertile phase is three full days past the last Peak recording of the fertility monitor, cervical mucus, or both.

The electronic hormonal fertility monitor detects a rising level of urinary estrogen to provide a High fertility level and a threshold level of urinary luteinizing hormone to provide a Peak recording. Users of the fertility monitor tested the first morning concentrated urine with a 
NOT THE PUBLISHED VERSION; this is the author's final, peer-reviewed manuscript. The published version may be accessed by following the link in the citation at the bottom of the page.

test strip that was read by the monitor (Swiss Precision Diagnostics, SPD). Participants who used cervical mucus monitoring were asked to check daily for low, high, or peak rated mucus whenever voiding and at the end of the day and to record the most fertile level of cervical mucus observed.

\section{Unintended Pregnancy Rates}

The electronic charting system automatically notifies the user of the possibility of a pregnancy when the postovulatory phase of the charted menstrual cycle goes beyond 19 days. When this happens the charting system prompts the user to take a pregnancy test. The online system also informs the nurse administrators of a pregnancy. If the nurse administrators have confirmed a pregnancy through discussion with the user, they launch a pregnancy evaluation into the user's membership page. The membership page is private and unique to the user, and the pregnancy evaluation takes only a few minutes to complete. Once completed by the user, two professional nurse NFP teachers evaluate all pregnancies that occur among the participants. The NFP teachers review the charting system for the days of fertility, the days of recorded intercourse, and the information on the pregnancy evaluation form. Each participant was asked to record on her fertility chart before each new cycle of charting her intention of either achieving or avoiding pregnancy. A determination is made if intercourse occurred during the fertile time as designated by the online charting system and MM protocols.

Pregnancy rates were determined by using survival analysis (Kaplan-Meier) with IBM SPSS version 21. Unintended pregnancies were recorded as correct use when there was no indication or charting of intercourse during the estimated fertile phase. Unintended pregnancies were recorded as incorrect use when there was intercourse indicated during the estimated fertile window or if the menstrual cycle chart had missing data that would not allow for interpretation of the fertile window. Correct use pregnancy rates were calculated based on 100 women per 12 menstrual cycles of use and included only menstrual cycles that were determined to be correct use, that is, no intercourse during the fertile window. Typical or total use unintended pregnancy were calculated with all charted menstrual cycles, that is, correct use menstrual cycles of use and incorrect or inconsistent menstrual cycles of use. Correct and total use unintended

MCN: American Journal of Maternal Child Nursing, Vol 42, No. 1 (January/February 2017): pg. 43-49. DOI. This article is (C) Wolters Kluwer Health, Inc. and permission has been granted for this version to appear in e-Publications@Marquette. Wolters Kluwer Health, Inc. does not grant permission for this article to be further copied/distributed or hosted elsewhere without the express permission from Wolters Kluwer Health, Inc. 
pregnancy rates and subgroups of participants who used either the electronic fertility monitor, cervical mucus monitoring, or both indicators of fertility were determined among all 1,530 participants. Net unintended pregnancy rates were then calculated on the 665 participants who were not classified as postpartum breastfeeding.

\section{Results}

\section{Total Participants}

\section{Demographics}

The total 1,530 participants came from all 50 states and 5 foreign countries, had a mean age of 30.3 (SD $=5.4$ ), were married a mean of 5.1 years ( $S D=5.1$; Range $0-32$ ), and had a mean of 2.4 children (SD = 2.0; Range 0-12). Most (80\%) were college graduates, 93\% Catholic, and 85\% Euro-American.

\section{Unintended Pregnancy Rates}

The gross correct use unintended pregnancy rate was 2.5 per 100 users at 12 cycles of use and 3.4 per 100 users at 24 cycles of use. However, the total or typical use pregnancy rate was 12.6 per 100 users at 12 months of use and 23.8 per 100 users at 24 cycles of use.

\section{Nonbreastfeeding Participants}

Demographics. The 663 nonbreastfeeding participants attempting to avoid pregnancy had a mean age of 30.39 (SD =6.28), were married a mean of 4.60 years $(S D=5.81)$, they had a mean of 2.13 pregnancies $(S D=2.55)$, and a mean of 1.77 children $(S D=$ 2.01). The majority were Euro-American and Catholic. The majority (68.2\%) indicated that they had regular length (25-35 days) menstrual cycles, 9.9\% classified themselves as having long ( $>35$ days) menstrual cycles, and $2.3 \%$ short ( $<25$ days) menstrual cycles. Only $3.4 \%$ were posthormonal contraception, and $3.5 \%$ were classified as premenopause.

\section{Unintended Pregnancy Rates}

The correct use unintended pregnancy rate for the entire 663 participants was 1.6 per 100 women at both 12 and 24 cycles of use. The total unintended pregnancy survival rates for the subgroups of NFP indicators are in Table 1 . The electronic fertility monitor (with algorithm) has the highest survival rate and the lowest unintended 
pregnancy rate of 2 per 100 women at 12 cycles of use and 6 by 24 cycles of use. Both the cervical mucus and the cervical mucus plus fertility monitor subgroups have lower survival rates at 24 cycles of use with an unintended pregnancy rate of 19 for cervical mucus monitoring subgroup and 18 for cervical mucus monitoring plus the electronic hormonal fertility monitor subgroup. The total pregnancy and survival rates are based on 1,681 menstrual cycles for the fertility monitor group, 481 menstrual cycles for the mucus only subgroup, and 3,086 menstrual cycles for the monitor plus mucus subgroup.

\section{Limitations}

Limitations of the study include no direct follow-up (other than electronic web notifications, forum communications, and private messages) with the participants over the extended time period of the study. Whether participants stopped charting or if they continued with the MM but used paper charting downloaded from the Web site was not recorded. Results also depend upon the participants honestly recording acts of intercourse-with the assumption that there is underreporting of intercourse. Sometimes it was apparent that a couple indicated an unintended pregnancy with no intercourse recorded on or near the estimated time of fertility. Women participants in this study were well educated, middle class, and white. The system is also in the Spanish language and one of the nurse NFP teachers is a native Spanish speaker. A challenge, however, is to make the system more responsive to a more diverse population of women. A practical limitation is that the electronic fertility monitor has an initial expense for purchase of around $\$ 200$ and requires monthly expenses for test strips from $\$ 20$ to $\$ 40$. Use of less expensive LH testing strips as an alternative to the fertility monitor is currently being investigated (Leiva et al., 2014).

\section{Clinical Implications}

The correct use unintended pregnancy rate for women with regular menstrual cycles using the MM online system of NFP is very low at less than 2 unintended pregnancies over 24 menstrual cycles of use. However, the total or typical unintended pregnancy rate increased to 15 pregnancies over 24 menstrual cycles of use. These pregnancy rates are of the total group of nonbreastfeeding women 
using the MM online system of NFP. When analyzing subgroups of women using the MM online system, women using the electronic fertility monitor had the lowest extended use (i.e., 24 cycles of use) unintended pregnancy rate of 6 per 100 women, compared with 19 among the cervical mucus monitoring subgroup and 18 among the fertility monitor plus cervical monitoring subgroup. Total pregnancy rates of the cervical monitoring subgroup and the cervical monitoring plus fertility monitor subgroup increased considerably from 12 to 24 menstrual cycles of use.

The correct and typical use 12-cycle unintended pregnancy rates found in the current study among the electronic fertility monitor subgroup compared well with the participants using the same method in an earlier randomized efficacy study, that is, typical use pregnancy rates of the fertility monitor group were much lower compared with cervical mucus monitoring. The 12-month unintended pregnancy rate of that study was 6 that compared with the extended use study of 4 for the current study (Fehring, Schneider, \& Raviele, et al., 2013). The extended use study of the Standard Days Method, however, actually showed a decrease in unintended pregnancy rates over time, but this might be due to drop out of those who most likely would get pregnant or who already have achieved a pregnancy (Sinai et al., 2012). One of the reasons why the fertility monitor plus algorithm might be more effective is that it is simpler to use, objective, and requires less periodic abstinence than the cervical mucus monitoring plus algorithm (Fehring \& Schneider, 2014).

A strength of the current study is that there was not a lot of external control and frequent monitoring of the participants, for example, the participants in the MM randomized comparison trial were followed up monthly, and in the current study the participants received no direct contact by the researchers other than when they requested it through forums or the private messaging system. This is more like a typical use-effectiveness study and how the use of the MM would play out in a nonresearch context. This study did not eliminate women with irregular cycle lengths, that is, short and long menstrual cycles, and older women with very irregular perimenopausal cycles. Most NFP effectiveness studies include only regular cycle length women, which would enhance the ability of obtaining lower unintended pregnancy rates. 
A key factor of NFP method effectiveness is motivation of the couple either to achieve or avoid a pregnancy. A previous study of motivation indicated that unintended pregnancy rates increase considerably when motivation decreases from high levels of motivation (Fehring et al., 2013). In this study, an item on the pregnancy evaluation form asks if the act of intercourse in the fertile time was due to a conscious departure from the instructions to avoid. In other words, the couple made a decision to change their minds about following instructions to avoid pregnancy midcycle. Approximately $70 \%$ of the unintended pregnancies indicated this behavior within the pregnancy evaluation form.

Results show that an online system of NFP developed and managed by nurses can be very effective in helping couples avoid pregnancy. Simplified methods of NFP seem to be the most effective. However, technology of the current system of online NFP is already out of date. Since it was launched in 2008, numerous fertility applications (apps) have been developed that can be downloaded into cell phones and other handheld Internet devices (Berglund Scherwitzl, Lindén Hirschberg, \& Scherwitzl, 2015). Research studies on the use and effectiveness of these fertility apps are sparse. The Marquette University researchers have recently developed a fertility app that is based on the MM system of NFP and are working to sync the app with a new web page system that includes social networking. Effectiveness of the current online NFP system with postpartum breastfeeding women and with couples wishing to achieve pregnancy will be investigated. More data are needed to determine if this online system is more effective than in-person NFP services and whether this system of providing NFP services has more or less personal satisfaction among women users.

\section{Acknowledgment}

The authors wish to thank and acknowledge Brittany McCoy, a senior at Washington and Jefferson University, for spending a summer research internship entering data for this study into a SPSS data file.

\section{Clinical Implications}

Providing effective, accessible, and easy-to-use NFP through a nursemanaged NFP Web site is possible.

The NFP Web site requires daily monitoring by nurses to answer questions and assess problems. 
Integrating use of an electronic hormonal fertility monitor and online menstrual charting system is the most effective approach for women with regular menstrual cycles over extended use. critical.

Updating the Web site and maintaining online technical security is

Reaching underserved populations of women seeking NFP services (e.g., the poor and racially diverse) is a challenge.

\section{Congratulations to MCN 2016 Award Winners!}

2016 Research Paper of the Year Award

Milk Flow Rates from Bottle Nipples Used After Hospital

Discharge

Britt Frisk Pados, PhD, RN, NNP-BC

Jinhee Park, PhD, RN

Suzanne M. Thoyre, PhD, RN, FAAN

Hayley Estrem, PhD, RN

W. Brant Nix, BMET, BA

Published in the July / August issue of MCN (Volume 41, Issue 4)

2016 Practice Paper of the Year Award

Planning, Designing, Building, and Moving a Large Volume

Maternity Service to a New Labor and Birth Unit

Heather Thompson, RN, MSN, CENP

Kimberly Legorreta, RN, BSN

Mary Ann Maher, RNC-OB, C-EFM, MSN

Melanie M. Lavin, AA

Published in the November / December issue of MCN (Volume 41, Issue 6)

\section{References}

Berglund Scherwitzl E., Lindén Hirschberg A., Scherwitzl R. (2015). Identification and prediction of the fertile window using Natural Cycles. The European Journal of Contraception \& Reproductive Health Care, 20(5), 403-408. doi:10.3109/13625187.2014.988210

Bouchard T., Fehring R. J., Schneider M. (2013). Efficacy of a new postpartum transition protocol for avoiding pregnancy. Journal of the American Board of Family Medicine: JABFM, 26(1), 35-44. doi: 10.3122/jabfm.2013.01.120126

MCN: American Journal of Maternal Child Nursing, Vol 42, No. 1 (January/February 2017): pg. 43-49. DOI. This article is @ Wolters Kluwer Health, Inc. and permission has been granted for this version to appear in e-Publications@Marquette. Wolters Kluwer Health, Inc. does not grant permission for this article to be further copied/distributed or hosted elsewhere without the express permission from Wolters Kluwer Health, Inc. 
NOT THE PUBLISHED VERSION; this is the author's final, peer-reviewed manuscript. The published version may be

accessed by following the link in the citation at the bottom of the page.

Fehring R. J., Mu Q. (2014). Cohort efficacy study of natural family planning among perimenopause age women. Journal of Obstetric, Gynecologic, and Neonatal Nursing: JOGNN, 43(3):351-358. doi:10.1111/15526909.12307

Fehring R. J., Schneider M. (2014). Comparison of abstinence and coital frequency between 2 natural methods of family planning. Journal of Midwifery \& Women's Health, 59(5), 528-532.

doi:10.1111/jmwh.12216

Fehring R. J., Schneider M., Barron M. L. (2008). Efficacy of the Marquette Method of natural family planning. MCN. The American Journal of Maternal Child Nursing, 33(6), 348-354. doi: 10.1097/01.NMC.0000341254.80426.32

Fehring R. J., Schneider M., Barron M. L., Pruszynski J. (2013). Influence of motivation on the efficacy of natural family planning. MCN. The American Journal of Maternal Child Nursing, 38(6), 352-358. doi:10.1097/NMC.0b013e3182a1ecc0

Fehring R. J., Schneider M., Barron M. L., Raviele K. (2009). Cohort comparison of two fertility awareness methods of family planning. Journal of Reproductive Medicine, 54(3), 165-170. PMID: 19370902

Fehring R. J., Schneider M., Raviele K. (2011). Pilot evaluation of an Internet-Based natural family planning education and service program. Journal of Obstetric, Gynecologic, \& Neonatal Nursing: JOGNN, 40(3), 281-291. doi:10.1111/j.1552-6909.2011.01237.x

Fehring R. J., Schneider M., Raviele K., Barron M. L. (2007). Efficacy of cervical mucus observations plus electronic hormonal fertility monitoring as a method of natural family planning. Journal of Obstetric, Gynecologic, \& Neonatal Nursing: JOGNN, 36(2), 152-160. doi:10.1111/j.1552-6909.2007.000129.x

Fehring R. J., Schneider M., Raviele K., Rodriguez D., Pruszynski J. (2013). Randomized comparison of two internet-supported fertilityawareness-based methods of family planning. Contraception, 88(1), 24-30. doi:10.1016/j.contraception.2012.10.010

Leiva R., Burhan U., Kyrillos E., Fehring R., McLaren R., Dalzell C., Tanguay E. (2014). Use of ovulation predictor kits as adjuncts when using fertility awareness methods (FAMs): A pilot study. Journal of the American Board of Family Medicine: JABFM, 27(3), 427-429. doi: 10.3122/jabfm.2014.03.130255

Mu Q., Fehring R. J. (2014). Efficacy of achieving pregnancy with fertilityfocused intercourse. MCN. The American Journal of Maternal Child Nursing, 39(1), 35-40. doi:10.1097/NMC.0b013e3182a76b88

MCN: American Journal of Maternal Child Nursing, Vol 42, No. 1 (January/February 2017): pg. 43-49. DOI. This article is (C) Wolters Kluwer Health, Inc. and permission has been granted for this version to appear in e-Publications@Marquette. Wolters Kluwer Health, Inc. does not grant permission for this article to be further copied/distributed or hosted elsewhere without the express permission from Wolters Kluwer Health, Inc. 
NOT THE PUBLISHED VERSION; this is the author's final, peer-reviewed manuscript. The published version may be accessed by following the link in the citation at the bottom of the page.

Sinai I., Lundgren R. I., Gribble J. N. (2012). Continued use of the standard days method. The Journal of Family Planning and Reproductive Health Care, 38(3), 150-156. doi:10.1136/jfprhc-2011-100097

Trussell J. (2011). Contraceptive failure in the United States. Contraception, 83(5), 397-404. doi:10.1016/j.contraception.2011.01.021

Figure.

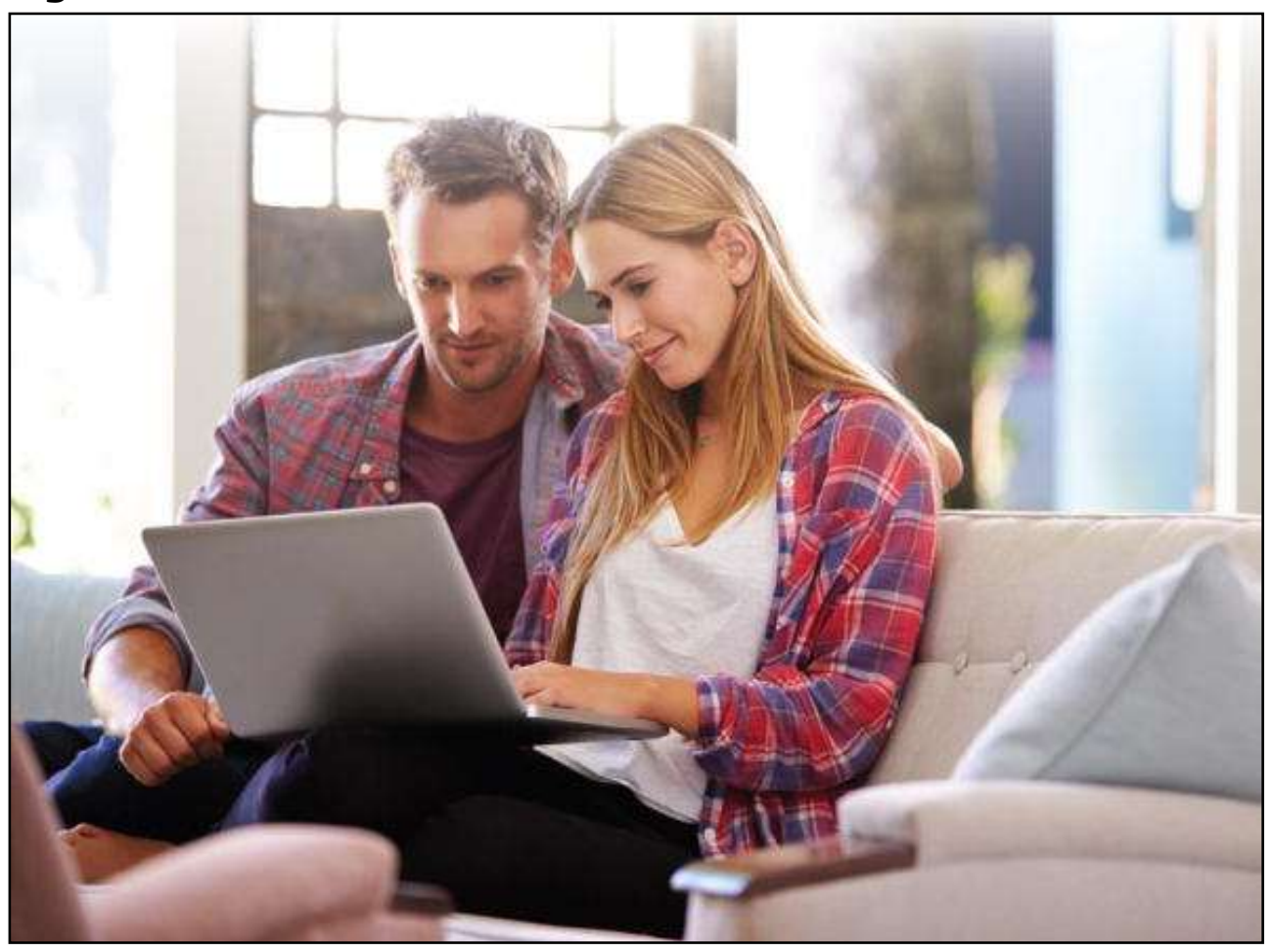

MCN: American Journal of Maternal Child Nursing, Vol 42, No. 1 (January/February 2017): pg. 43-49. DOI. This article is C Wolters Kluwer Health, Inc. and permission has been granted for this version to appear in e-Publications@Marquette. Wolters Kluwer Health, Inc. does not grant permission for this article to be further copied/distributed or hosted elsewhere without the express permission from Wolters Kluwer Health, Inc. 
NOT THE PUBLISHED VERSION; this is the author's final, peer-reviewed manuscript. The published version may be accessed by following the link in the citation at the bottom of the page.

Figure 1. Online Menstrual Cycle Charting System Showing a Correct Use Unintended Pregnancy in Cycle 7 and an Incorrect Use Unintended Pregnancy in Cycle 15

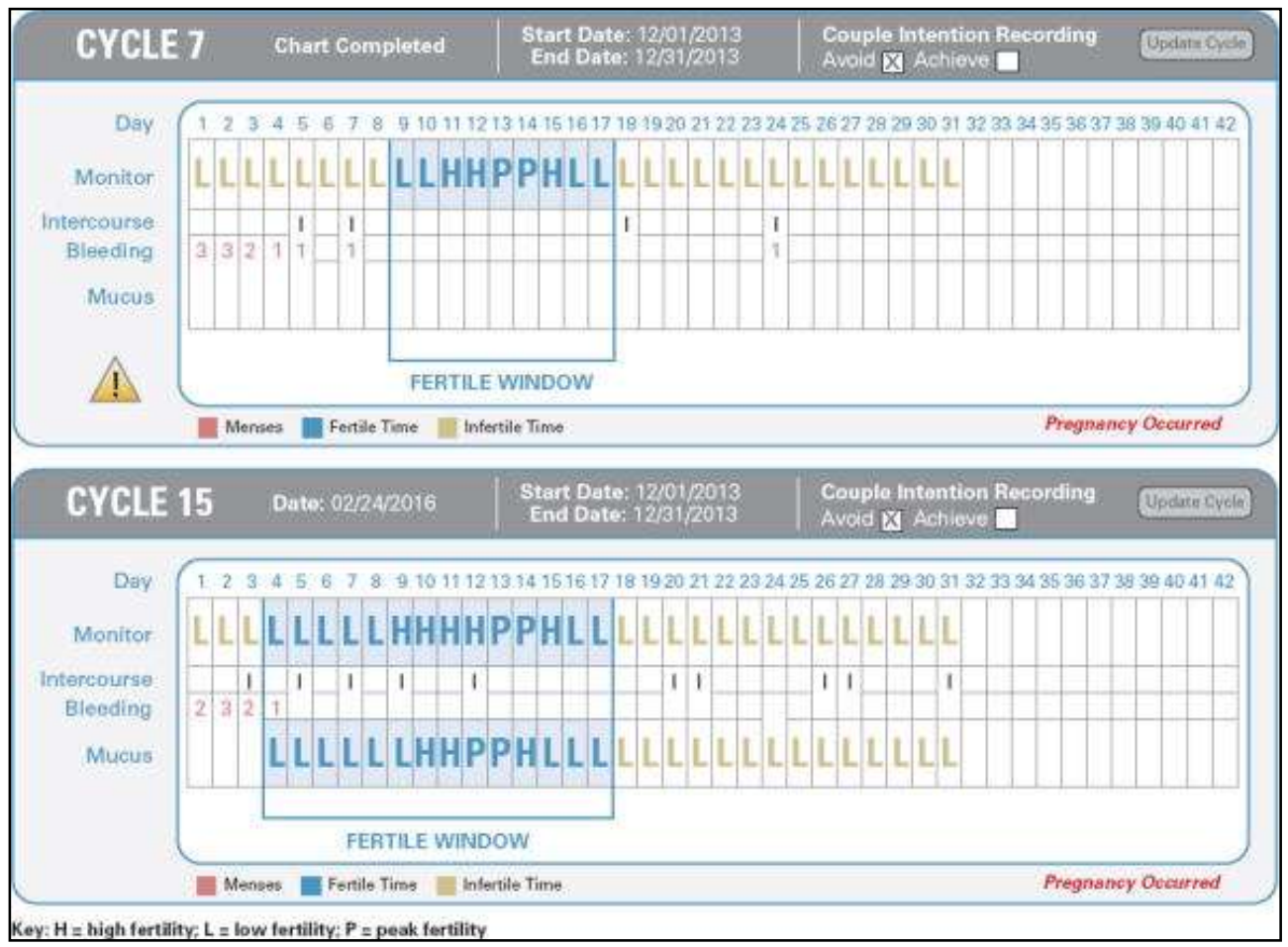

MCN: American Journal of Maternal Child Nursing, Vol 42, No. 1 (January/February 2017): pg. 43-49. DOI. This article is @ Wolters Kluwer Health, Inc. and permission has been granted for this version to appear in e-Publications@Marquette. Wolters Kluwer Health, Inc. does not grant permission for this article to be further copied/distributed or hosted elsewhere without the express permission from Wolters Kluwer Health, Inc. 
NOT THE PUBLISHED VERSION; this is the author's final, peer-reviewed manuscript. The published version may be accessed by following the link in the citation at the bottom of the page.

Table 1. Typical Use Survival Rates by Fertility Indicators $N=663$

\begin{tabular}{|l|l|l|l|}
\hline $\begin{array}{l}\text { Electronic Fertility } \\
\text { Monitor }(\boldsymbol{n}=\mathbf{2 1 2})\end{array}$ & \#Pregnancy & Rate & Standard Error \\
\hline $\begin{array}{l}6 \text { cycles: } \\
12 \text { cycles: }\end{array}$ & 2 & .99 & 0.013 \\
\hline $\begin{array}{l}18 \text { cycles: } \\
24 \text { cycles: }\end{array}$ & 1 & .98 & 0.021 \\
\hline $\begin{array}{l}\text { Cervical Mucus } \\
\text { Monitoring } \\
\text { ( } \boldsymbol{n}=\mathbf{1 1 8} \text { ) }\end{array}$ & \#Pregnancy & Rate & Standard Error \\
\hline $\begin{array}{l}6 \text { cycles: } \\
12 \text { cycles: }\end{array}$ & 4 & .94 & 0.029 \\
\hline $\begin{array}{l}18 \text { cycles: } \\
24 \text { cycles: }\end{array}$ & 0 & .92 & 0.042 \\
\hline $\begin{array}{l}\text { Monitor and } \\
\text { Mucus Monitoring } \\
\text { ( } \boldsymbol{n}=333 \text { ) }\end{array}$ & \#Pregnancy & .92 & 0.042 \\
\hline $\begin{array}{l}6 \text { cycles: } \\
12 \text { cycles: }\end{array}$ & 4 & .92 & 0.042 \\
\hline $\begin{array}{l}18 \text { cycles: } \\
24 \text { cycles: }\end{array}$ & 6 & .81 & 0.114 \\
\hline
\end{tabular}

MCN: American Journal of Maternal Child Nursing, Vol 42, No. 1 (January/February 2017): pg. 43-49. DOI. This article is (c) Wolters Kluwer Health, Inc. and permission has been granted for this version to appear in e-Publications@Marquette. Wolters Kluwer Health, Inc. does not grant permission for this article to be further copied/distributed or hosted elsewhere without the express permission from Wolters Kluwer Health, Inc. 